\title{
O 'brincar' na educação infantil e o desenvolvimento da criança
}

No presente artigo, busca-se retratar, por meio de uma pesquisa qualitativa e bibliográfica, a relevância que reside na prática da ludicidade e das brincadeiras na Educação Infantil e suas contribuições para o desenvolvimento das crianças. Defende-se que o brincar é um comportamento intrinsecamente motivado; postulado como uma atividade que deve facilitar a aprendizagem e/ou a prática de comportamentos específicos. Diante dos estudos arraigados a presente pesquisa, constatou-se que as fantasias imaginativas e as brincadeiras podem compensar as pressões do cotidiano. Desse modo, entende-se que, por meio do brincar, devese incentivar que os sentimentos sejam compartilhados, possibilitando à criança reconhecê-los, aceitá-los e expressá-los. Dessa maneira a criança exterioriza os seus sentimentos, minimizando seu sofrimento. Além disso, descobriu-se, também, que as crianças mais velhas preferem os jogos simbólicos, a fantasia (dramatização, teatro), estão assim preparando a vida adulta. O desenvolvimento humano é um processo de individualização crescente que acontece desde o nascimento, através da interação social. $\mathrm{O}$ ambiente no qual a criança está inserido é seu recurso básico de desenvolvimento.

Palavras-chave: Ludicidade; Brincar; Educação Infantil; Jogos.

\section{The 'play' in early childhood education and the development of children}

In this article, it seeks to portray, through a qualitative and bibliographic research, the relevance that lies in the practice of deceiving and playing in Early Childhood Education and its contributions to the development of children. It is argued that playing is an intrinsically motivated behavior; postulated as an activity that should facilitate learning and/or the practice of specific behaviors. In view of the studies rooted in this research, it was found that imaginative fantasies and games can compensate for the pressures of everyday life. Thus, it is understood that, through play, one should encourage feelings to be shared, enabling the child to recognize them, accept and express them. In this way, the child externalizes his feelings, minimizing his suffering. In addition, it was also discovered that older children prefer symbolic games, fantasy (dramatization, theater), are thus preparing adulthood. Human development is a process of increasing individualization that has happened from birth, through social interaction. The environment in which the child is inserted is their basic development resource.

Keywords: Ludicity; Playing; Early Childhood Education; Games.

Topic: Pedagogia (Educação Criança e Adolescente)

Reviewed anonymously in the process of blind peer.
Received: 16/10/2019

Approved: $19 / 01 / 2020$

Vanessa Magnante de Moraes (iD

Faculdade São Braz, Brasil

http://lattes.cnpq.br/1883735890860923

http://orcid.org/0000-0001-9116-5027

vanessamagnante@hotmail.com

Referencing this:

MORAES, V. M.. O 'brincar' na educação infantil e o desenvolvimento da criança. Educationis, v.8, n.1, p.1-7, 2020. DOI: http://doi.org/10.6008/CBPC2318-3047.2020.001.0001 


\section{INTRODUÇÃO}

O brincar permite que a pessoa cometa erros sem sentir culpa. Para Moyles (2002), o brincar está presente na vida das crianças de diferentes culturas, etnias e religiões. Toda criança brinca, e essa atividade faz parte de seu crescimento e desenvolvimento. Logo, o brincar se caracteriza como um comportamento que possui um fim em si mesmo, que surge livre, sem noção de obrigatoriedade e se exerce pelo simples prazer que a criança encontra ao colocá-lo em prática.

Os pensadores Pellegrini et al. (1998) concordam com este conceito e acrescentam que, a partir dele, a importância do brincar estaria mais no seu próprio processo (meio), do que em seus benefícios futuros (fins). Entretanto não existe uma definição certa para o brincar e desde os tempos remotos se tenta definir essa atividade praticada pela maioria das crianças.

Uma das primeiras teorias sobre o brincar infantil, por exemplo, surgiu no século XVIII e entendia esta atividade como o produto de uma energia excedente. Já os estudiosos que dominaram as teorias do brincar na primeira metade do século XX, como Piaget e Vygotsky, definem o brincar a partir da sua relação com o desenvolvimento psicológico mais amplo (ALMEIDA, 2005).

Posteriormente, temos teóricos como Almeida (2005) que explica o brincar como um comportamento intrinsecamente motivado; o autor ainda postula o brincar como uma atividade que deve facilitar a aprendizagem e/ou a prática de comportamentos específicos. O historiador Áries (2010) constatou em sua pesquisa que os jogos destinados aos adultos, eram os mesmos destinados às crianças: 'Parece, portanto, que no início do século XVII não existia uma separação tão rigorosa como hoje entre as brincadeiras e os jogos, reservados às crianças, e as brincadeiras e os jogos dos adultos. Os mesmos eram comuns a ambos'.

Como também não havia a distinção entre infância e vida adulta, visto que as crianças daquela época eram tratadas como adultas, a aprendizagem infantil vinha da convivência da criança com o adulto, que o auxiliava em seus afazeres, e ela era logo misturada aos adultos, participava dos seus trabalhos e jogos, garantindo deste modo sua educação (JÓIA, 2013).

Desse modo, acredita-se que o brincar é o primeiro experimentar do mundo que se realiza na vida da criança. É uma linguagem de interação que permite descobertas e conhecimentos sobre si mesmos, sobre o outro e sobre o mundo que a rodeia. O brincar é uma atividade prática, na qual as crianças constroem e transformam seu mundo, conjuntamente, renegociando e redefinindo a realidade. Assim, o brincar compreende uma construção da realidade, a produção de um mundo e a transformação do tempo e do lugar em que ele pode acontecer (CONTI et al., 2011).

A criança brinca com outras crianças da mesma idade, mais novas, mais velhas, do sexo oposto ao dela, porque para ela o que importa é a brincadeira, a diversão, a reconstrução de cenários vividos por ela, a exteriorização da realidade a qual ela passa. Por esse motivo as diferenças de gênero no brincar infantil têm sido bastante estudadas por diversos pesquisadores (MALUF, 2014).

Tais estudos possuem extrema relevância na medida em que as diferenças de gênero no brincar 
possibilitam que meninos e meninas desenvolvam-se de maneiras distintas, porém igualmente adaptativas. As crianças adquirem habilidades diversificadas e, dessa forma, distinguem seu papel de gênero de acordo com a sociedade e cultura a que pertence (JÓIA, 2013).

Segundo Jóia (2013), por volta do século XV não existia discriminação entre meninos e meninas, visto que ambos usavam o mesmo traje, uma espécie de vestido, e a brincadeira com bonecas era comum a eles. Além da diferença do brincar entre meninos e meninas outro fator é relacionado à maneira distinta de se brincar. Maluf (2014) em seu estudo relaciona a preferência lúdica da criança com a faixa etária. Para a autora: Cada faixa etária possui um modo de brincar. As crianças pequenas, até quatro anos, preferem os jogos de encaixe, motores e de construção. No período de sete a 11 anos, a criança se interessa, sobretudo, pelos jogos de regras (ludo, dominó, cartas de baralho, dama).

As crianças mais velhas preferem os jogos simbólicos, a fantasia (dramatização, teatro), estão assim preparando a vida adulta. Segundo Jóia (2013), o desenvolvimento humano é um processo de individualização crescente que acontece desde o nascimento, através da interação social. 0 ambiente no qual a criança está inserida é seu recurso básico de desenvolvimento.

O brincar infantil não pode ser considerado apenas uma brincadeira superficial, sem nenhum valor, pois, no verdadeiro e profundo brincar, acordam, despertam, e vivem forças de fantasias que, por sua vez, chegam a ter uma ação direta sobre a formação e sobre a estruturação do pensamento da criança. Esse processo natural e sadio de se processar a inteligência não é possível, quando as crianças não realizam ou não conseguem mais o verdadeiro brincar (JÓIA, 2013).

Para Moyles (2002) o brincar, em si mesmo, serve tanto para identificar as necessidades individuais quanto para proporcionar medidas paliativas. Já na visão de Jóia (2013) o brincar intensifica a percepção infantil que, por sua vez, direciona seu pensar de maneira cada vez mais equilibrada favorecendo aprendizagens ao longo do seu crescimento. Ao desenvolver suas potencialidades, a criança aprende a interagir, vencendo suas dificuldades, tomando decisões nas situações mais conflituosas. Através das brincadeiras a criança pode revelar seus sentimentos, realizar compensações, resgatar seu equilíbrio emocional.

Deve ser permitido aos meninos e às meninas representar papéis masculinos e femininos. Diferentes papéis possibilitam a vivência de diferentes sentimentos. Brincar inclui experimentar diversos sentimentos e sensações, proporciona muitas aprendizagens sociais e crescimento emocional, é interagir, socializar-se, divertir-se na convivência com os iguais (JÓIA, 2013). Não existem dúvidas de que para uma grande maioria das crianças o brincar é um motivador real, ele traz recompensas essenciais ao seu desenvolvimento, é realizado espontânea e voluntariamente prazeroso (MOYLES, 2002).

\section{METODOLOGIA}

Diante do presente estudo, a pesquisa foi dirigida de modo sistemático, em se considerando a prática da revisão narrativa de literatura, por meio de ideário bibliográfico. Consoante Gil (2017), cabe ressaltar o aspecto de desenvolvimento qualitativo, exploratório e investigativo. Diante desse viés, elenca-se uma base 
teórica constituída por fontes baseadas em artigos científicos, livros, revistas cientificas, entre outros.

Dessarte, as principais ferramentas empregadas foram a pesquisa bibliográfica, documental, bem como a observação efetiva da realidade educacional, por meio da participação em conferências, fóruns, seminários, oficinas de formação, reuniões e outros eventos pertinentes à Educação Infantil e a sua relação com a Ludicidade e com os jogos e brincadeiras. Mediante Salvador (2015), ao se iniciar uma pesquisa, a questão principal para o pesquisador é realizar uma opção; ou seja, deve-se decidir aquilo que precisa ser recortado, o que é mais relevante diante da imensidão das possibilidades que existem dentro do processo da pesquisa.

Nesse sentido, a delimitação do espaço, do contexto de pesquisa e as ferramentas a serem empregadas durante a pesquisa são condições fundamentais para bem percorrer a caminhada. Consoante o autor supracitado, através da pesquisa exploratório-descritiva, apresentar-se o percurso construído com utilização da pesquisa bibliográfica como procedimento metodológico. Cabe mencionar que a pesquisa, no papel de estudo teórico elaborado a partir da reflexão pessoal e da análise de documentos escritos, originais primários denominadas fontes, segue uma sequência ordenada de procedimentos.

\section{DISCUSSÃO TEÓRICA}

\section{A importância do 'brincar' e a brinquedoteca}

Para Moyles (2002), as crianças brincam para encontrar a realidade, os adultos brincam para evitála. Ela reconhece no brincar a possibilidade de passar o tempo, distrair-se e, principalmente, se divertir. 0 brincar tem origem na situação imaginária criada pela criança, em que seus desejos irrealizáveis podem se tornar reais, com o objetivo de reduzir tensões, conflitos e frustrações da vida real.

As fantasias imaginativas e as brincadeiras podem compensar as pressões do cotidiano. Desse modo Vygotsky (2007) afirma que, por meio do brincar, deve-se incentivar que os sentimentos sejam compartilhados, possibilitando à criança reconhecê-los, aceitá-los e expressá-los. Dessa maneira a criança exterioriza os seus sentimentos, minimizando seu sofrimento.

Para Almeida (2005), o brincar pode proporcionar uma fuga das pressões da realidade para aliviar aborrecimento, ansiedade e, às vezes, funciona como relaxamento das tensões da hospitalização. É necessário que os Centros de Educação Infantil adotem as brinquedotecas fazendo com que ela faça parte dos recursos a serem utilizados pela equipe docente no processo pedagógico com o educando da educação infantil.

Pensando nisso muitas instituições passaram a adotar a brinquedoteca como um espaço destinado às crianças. Nesse local, elas brincam, interagem com outras crianças, estudam, deixando de lado o stress e a ansiedade inerentes a essa faixa etária.

A brinquedoteca surgiu nos Estados Unidos, na cidade de Los Angeles em 1934 (como empréstimo de brinquedos a crianças que não podiam comprá-los). Esse serviço é utilizado até e hoje e é chamado em Los Angeles de Toy Loan (...). No Brasil a primeira brinquedoteca foi montada em 1973, na APAE de São Paulo, voltada a crianças portadoras de deficiência mental. (MALUF, 2014) 
A brinquedoteca é um espaço que visa estimular crianças e jovens a brincarem livremente, pondo em prática sua própria criatividade e aprendendo a valorizar as atividades lúdicas (MALUF, 2004). Ela é indicada para qualquer idade do zero aos 100 anos e mais, não se restringe a faixa socioeconômica de seus frequentadores, ela traz o resgate da importância do brincar para a criança (proartecultural). Na brinquedoteca, a criança e seus pais relaxam, distraem, esquecem um pouco de seus problemas, pois lá interagem com outras crianças, outros pais, realizam atividades lúdicas, como recortar e colar, desenhar e pintar, montar quebra-cabeça, e até leitura, aliviando assim sua tensão e ansiedade.

O brinquedo é de suma importância na vida de uma criança, pois auxilia o desenvolvimento, fazendo com que, pouco a pouco, ela comece a distinguir os significados dos objetos reais; sua percepção evolui a partir das experiências que o próprio brinquedo proporciona, ampliando seu imaginário (VYGOTSKY, 2007). A inserção do brincar na Educação Infantil motivou estudos sobre o seu real valor no processo de humanização escolar, assim para Lindquist (1993) é possível indicar sua aplicação terapêutica ao proporcionar às crianças atividades estimulantes e divertidas, que traz calma e segurança.

O valor terapêutico do brincar foi destacado por Maluf (2014), que assim descreveu os benefícios de brincar: (1) é um modo natural de auto expressão para a criança; (2) permite à criança exercer algum controle de modo a ajudá-la a contrabalançar sentimentos de desamparo; (3) pode ser usado para promover uma relação terapêutica e de ajuda entre a criança e o adulto; (4) pode aumentar a autoestima; (5) provê uma maneira de manter um aspecto da vida normal, por meio de atividades da infância; (6) pode prover a distração do medo, preocupação ou stress; (7) revigora e provê a liberação de energia; (8) permite e encoraja o uso da fantasia; (9) permite a criança a ser o professor; (10) oferece oportunidades para o envolvimento e a interação familiar, que inclui os pais, irmãos e parentes, e (11) oferece suporte para a aprendizagem e o desenvolvimento.

Entre os tipos de brinquedos recomendados para a criança na Educação Infantil, Jóia (2013) sugere aqueles que representam a vida cotidiana, brinquedos para dramatização, materiais para expressão artística, brinquedos de construção e jogos; alertando para a importância de que sejam seguros acessíveis e funcionais. Continuando, a autora destaca o uso do videogame, por sua característica de incentivar a participação da criança, evitando seu isolamento e favorecendo a sensação de realização e, também, o uso de objetos que reproduzem o cotidiano médico, como estetoscópio, seringas, máscara de oxigênio, gaze, luva cirúrgica, entre outros.

A criança, quando brinca, desempenha papéis ativo e passivo. Quando brinca de médico, por exemplo, após ter tomado uma injeção ou ter sido submetida a uma cirurgia, na brincadeira, passa do papel passivo para o ativo, reorganiza pensamentos e emoções; expressa desejos, fantasias, vontades e conflitos; exercita potencialidades, desenvolve a sociabilidade e a sensibilidade e se desenvolve intelectual, social e emocionalmente (MALUF, 2014).

Dessa forma entende-se que o brinquedo proporciona à criança a chance de reorganizar a sua vida, seus sentimentos e diminuir a ansiedade, podendo também ser utilizado para ajudá-la a reconhecer seus sentimentos, assimilar novas situações, compreender o que se passa no CEl e esclarecer conceitos errôneos 
(CONTI, 2011).

Qualquer professor(a) pode utilizar o brinquedo no desenvolvimento de educandos, basta que o profissional tenha habilidade de conduzir a brincadeira. Para Maluf (2014) o brincar é uma experiência importante e certamente tem efeitos pedagógicos para a criança. Por meio da brincadeira, ela pode reelaborar cenas vividas pela recriação, para que possa reagir mais positivamente em relação à situação. Sendo assim, o brincar na Educação Infantil torna-se indispensável na vida de uma criança, pois são inúmeros os benefícios que a brincadeira trás para a vida do educando. "A criança impossibilitada de brincar tem seu desenvolvimento comprometido e seu equilíbrio emocional perturbado" (BOMTEMPO et al., 2016).

\section{CONCLUSÕES}

A investigação das atividades lúdicas preferenciais das crianças se faz necessário à medida que direciona os profissionais da educação a proporcionar um ambiente pedagógico mais adequado e satisfatório às crianças ali inseridas. Desta forma, constatação da melhor aceitação pelas Atividades Recreativas Diversas (ARD), como por exemplo, ler gibis, ouvir música e histórias e assistir televisão, sendo esta última a mais comum visto que em cada $\mathrm{CEI}$ tem acesso a esses materiais.

Muitas vezes, a preferência é pelos jogos de acoplagem que envolve atividades como recortar/colar, quebra-cabeça, montar peças e modelagem. Essas atividades geralmente têm uma maior aceitação pelas crianças devido ao fato de serem realizadas com frequência e, portanto, são mais acessíveis. Sobre as brincadeiras prediletas das crianças Jóia (2013) afirma que a preferência lúdica pelas atividades recreativas diversas e acoplagem ocorre devido ao fato dessas atividades fazerem parte da rotina da Educação Infantil. As demais brincadeiras (ler gibi, desenhar e montar quebra-cabeças) fazem parte do acervo de brinquedos da maior parte dos CEls e são oferecidas diariamente às crianças.

De igual importância, são as atividades com os jogos de exercício e jogos de regras devido ao autoconceito da criança, de que realizar atividades como jogar bola é uma das coisas que os educandos mais gostam de fazer. Nesse sentido, pode-se concluir que a ludicidade, desenvolvida por meio de jogos e brincadeiras é a principal língua das crianças; visto que estes se comunicam com o mundo através dessa particularidade e as brincadeiras infantis sempre fazem sentido, de acordo com suas experiências e necessidades particulares.

O jogo mostra o caminho para a vida interior das crianças; expresse seus desejos, fantasias, medos e conflitos simbólicos. As brincadeiras infantis refletem sua percepção de si mesmas, de outras pessoas e do mundo que os rodeia. Através da brincadeira, as crianças lidam com o passado e o presente e se preparam para o futuro. Pode-se dizer, então que os jogos destinados ao público da educação infantil estimulam todos os sentidos, visto que enriquece a criatividade e a imaginação; ajudando a usar energia física e mental de maneiras produtivas e divertidas. Destarte, o aspecto lúdico é divertido, e as crianças tendem a lembrar as lições aprendidas quando estão se divertindo; ao passo que se facilita o desenvolvimento de habilidades físico-motoras, da fala e dos demais esquemas de linguagem e do simbólico. 


\section{REFERÊNCIAS}

ALMEIDA, M. T. P.. O brincar na educação Infantil. Revista Virtual EFArtigos, Natal, v.3, n.1, 2005.

ARIÉS, P.. A história social da criança e da família. 10 ed. São Paulo: Guanabara, 2010.

BOMTEMPO, E.; ANTUNHA, E. G.; OLIVEIRA, V. B.. Brincando na escola, no hospital, na rua. Rio de Janeiro: Wak, 2016.

CONTI, L.; SPERB, T. M.. O Brinquedo de Pré-Escolares: Um Espaço de Ressignificação Cultural. Psic. Teor. e Pesq., Brasília, v.17, n.1, 2011.

GIL, A. C.. Como elaborar projetos de pesquisa. 6 Ed. São Paulo: Atlas, 2017.

JÓIA, A.. Educação Infantil em Caieiras: um estudo sobre as concepções e práticas de atendimento às crianças pequenas presentes em creches municipais. Dissertação (Mestrado) Pontifícia Universidade Católica de São Paulo, São Paulo,
2013.

LINDQUIST, I.. A Criança no Hospital: Terapia pelo Brinquedo (R. Z. Altman). São Paulo: Scritta, 1993.

MALUF, Â. C. M.. Brinquedoteca: um espaço estruturado para brincar. 4 ed. São Paulo: Ática, 2014.

MOYLES, J. R.. Só brincar? O papel do brincar na educação infantil. Porto Alegre: Artmed, 2002.

PELLEGRINI, A. D.; SMITH, P. K.. The development of play during childhood Forms and possible functions. Child Psychology \& Psychiatry Review, v.3, n.2, p.51-57, 1998.

SALVADOR, A. D.. Métodos e técnicas de pesquisa bibliográfica. 6 ed. Porto Alegre: Sulina, 2015.

VYGOTSKY, L. S.. Formação social da mente. São Paulo: Martins Fontes, 2007.

A CBPC - Companhia Brasileira de Produção Científica (CNPJ: 11.221.422/0001-03) detém os direitos materiais desta publicação. Os direitos referem-se à publicação do trabalho em qualquer parte do mundo, incluindo os direitos às renovações, expansões e disseminações da contribuição, bem como outros direitos subsidiários. Todos os trabalhos publicados eletronicamente poderão posteriormente ser publicados em coletâneas impressas sob coordenação da Sustenere Publishing, da Companhia Brasileira de Produção Científica e seus parceiros autorizados. Os (as) autores (as) preservam os direitos autorais, mas não têm permissão para a publicação da contribuição em outro meio, impresso ou digital, em português ou em tradução. 